\title{
10
}

\section{Senior civil service training in Taiwan: Current concerns and future challenges}

\section{Su Tsai-Tsu and Liu Kun-I}

Although Taiwanese Civil Service positions are still attractive to young people ${ }^{1}$ due to their high job security and lucrative retirement pensions, the current civil service system does not enjoy as much power or receive as much respect from citizens as it did in the past.

To restore public confidence in the civil service system, the Taiwanese Government is determined to improve the calibre of the civil service, focusing particularly on top-level officials. The Examination Yuan (Branch), the highest authority responsible for the recruitment, selection and management of all civil service personnel, approved the Civil Service Reform Plan in June 2009. One major objective of the plan is to enhance the training of high-ranking officials to improve decision-making and leadership skills.

1 According to statistics released by the Ministry of Examination, the number of people who registered to take the Junior and Senior Civil Service Examinations reached a record high in 2010 and 2011. (wwwc.moex.gov.tw/main/content/wfrmContentLink.aspx?menu_id=268. Accessed 3 July 2012.) 
The capacities of top-level civil service members are naturally held in higher regard than those of their subordinates in the bureaucratic hierarchy. People expect those serving at the top-the cadre of the civil service - to be equipped with strategic foresight and upto-date knowledge to steer the nation through tough challenges. Hence in 2010, with the support of President, Ma Ying-jeou, and the Legislature, the Examination Yuan established the National Academy of Civil Service (NACS) under the Civil Service Protection and Training Commission (CSPTC). ${ }^{2}$ With the training of high-level officials as one of its most important tasks, NACS has since designed and vigorously implemented a series of training programs.

Before the NACS was established, the Directorate-General of Personnel Administration (DGPA) ${ }^{3}$ of the Executive Yuan was the main institution in charge of training high-level officials. In September 2009, not long after the Examination Yuan started its Civil Service Reform Plan, the DGPA also announced a comprehensive high-ranking training package. This package consisted essentially of two parts: 1) Top Executive Leadership seminars held domestically; and 2) Globalisation and Leadership workshops held abroad.

The establishment of the NACS and the Examination Yuan's desire to cultivate high-level officials appeared to be in competition with the DGPA. Although this unique two-track training system offers the benefits of healthy competition, such as increased budget allocation and richer curriculum design, the system may encounter problems relating to the unclear division of tasks and responsibilities, duplicated resource investments and the loss of economy of scale, given the small number of senior-ranked civil service members being trained. The result is continuing debate about the benefits and costs of duplication and overlap in administrative organisations (Landau 1969, 1991; Felsenthal 1980; Knott and Miller 1987; Lerner 1987).

2 The NACS was not a new institute. Its antecedent is the National Civil Service Institute (NCSI), which was founded in 1999 under the supervision of the CSPTC of the Examination Yuan. It was restructured, up-scaled and renamed NACS in 2000 and designed to focus on training high-level civil servants and to offer lifelong learning programs and international exchanges for civil servants.

3 The antecedent organisation of the DGPA, the Central Public Administration, was established in 1967 and was responsible for the overall personnel administration of all the ministries and agencies under the Executive Yuan. In February 2012, the Central Public Administration was upgraded to the Directorate-General of Personnel Administration as part of a larger governmental reorganisation. 
Is it desirable to maintain this duplication in the senior service training system in Taiwan? Does it breed problems of coordination and result in redundancy and waste of resources or does it foster healthy competition and restore capacity for innovation? Under this centralised dual-track training system, what types of training curricula are provided to senior civil service members, and are they adequate to help senior civil servants cope with complex issues in our newly democratised and globalised society? So far, little effort has been made in academic circles to address these questions.

This chapter begins with an overview of Taiwan's senior civil service system. It then explains the dual-track training system and describes the core training programs developed for high-level officials by the Examination Yuan and Executive Yuan. Finally, the chapter summarises recent changes in executive civil service training and concludes with a discussion of the future challenges facing this dual-track training system.

\section{Overview of the senior civil service}

Before the twenty-first century, an effective civil service system was considered the backbone of the administrative machinery and was credited for the outstanding economic performance that led to Taiwan becoming one of the four 'Asian Dragons' ${ }^{4}$ by the end of the 1990s (Wade 1990; Clark 2000; Cheung 2005). In the past decade, however, harsh challenges including worldwide financial crises, national disasters, food insecurity, environmental degradation and other social and economic problems related to globalisation have brought a great deal of frustration to the Taiwanese Civil Service. Evidence suggests that in the face of rising public dissatisfaction, the once competent Taiwanese Civil Service has degenerated into bureaucratic passivity and has gradually decreased its leadership and initiative in policymaking (Tan 2000; Tang 2004; Berman et al. 2012).

4 The four 'Asian Dragons' refers to Taiwan, Singapore, South Korea and Hong Kong. These four economies maintained exceptionally high economic growth rates between the 1960s and the 1990s. 
While the sudden international economic uncertainties and a fastchanging globalised world have understandably affected the responsiveness of civil servants in their efforts to cope with such dynamic changes in Taiwan, scholars have pointed out that the island's democratisation process in the past two decades is also responsible for declining bureaucratic capacity (Tan 2000; Painter 2004). Under the one-party dominant authoritarian regime lasting from the late 1940s to the late 1980s, the working environment of Taiwan's civil servants was mostly insulated from electoral politics. Civil servants during that period enjoyed a relatively high degree of autonomy and were not under much public pressure or legislative oversight in making and implementing policies. Entering the post-democratisation era, however-particularly after two major political regime changes in the 2000 and 2008 presidential elections - civil servants found themselves losing party patrons and forced to answer to various political pressures (Tan 2000: 49). Demanding citizens, aggressive legislators, rent-seeking interest groups and a nosey mass media have had the combined effect of transforming the once insulated bureaucratic organisation into a fishbowl. Adjustment to the new politics has compromised the effectiveness of the civil service.

There are 14 grades of civil service positions across three ranks:

- elementary (G1-5)

- junior (G6-9)

- senior (G10-14).

This chapter relates to training for high-level officials or top civil servants - that is, grade 10-14 civil servants. However, as will be explained later, G9 civil servants are in some cases included in training.

The most important civil service examinations in Taiwan include the elementary, junior and senior examinations for recruiting ordinary administrative personnel. ${ }^{5}$ On passing the elementary examination, for which there are no educational prerequisites, candidates are assigned to a Gl position. The junior examination requires at least a high school

5 While the elementary, junior and senior examinations are designed for recruiting ordinary administrative personnel, another important type of civil service examination is the Special Examination, which is designed to recruit manpower for government agencies requiring personnel with specialised capacities (such as diplomats, national security personnel, prosecutors and judges) or to recruit from disadvantaged groups including disabled and indigenous peoples. 
education, and those who pass this examination are assigned a G3 position. The senior examination is divided into three levels, with Level 1 requiring a bachelor degree, Level 2 a master's degree and Level 3 a doctorate. Those who pass Levels 1, 2 or 3 of the senior examination are assigned to G6, G7 and G9 positions respectively. Currently, there is no civil service examination placing candidates directly into senior positions (G10 or higher).

Table 10.1 displays the ranking structure of the Taiwanese Civil Service and its composition. By the end of 2011, there were 342,643 civil servants in Taiwan. ${ }^{6}$ Among them, 121,935 were elementaryrank personnel, 208,188 were classified as junior rank and 12,520 were in the senior ranks, representing 35.6 per cent, 60.8 per cent and 3.7 per cent, respectively, of the entire civil service. As expected, senior-rank civil servants comprise the smallest group of all three ranks and yet they are key figures in the bureaucracy who wield great power and greatly impact the effectiveness of public policies. Undoubtedly, the government takes the training of senior personnel seriously despite their relatively small number.

Table 10.1: Composition of the Taiwanese Civil Service (as at the end of 2011)

\begin{tabular}{|l|c|c|c|}
\hline Rank & Grade & Number of people & Percentage \\
\hline Elementary & G1-G5 & 121,935 & $35.6 \%$ \\
\hline Junior & G6-G9 & 208,188 & $60.8 \%$ \\
\hline Senior & G10-G14 & 12,520 & $3.7 \%$ \\
\hline Total & & 342,643 & $100.0 \%$ \\
\hline
\end{tabular}

Source: Calculated from official statistics released by the Ministry of Civil Service (mocs.gov. tw/pages/detail.aspx?Node=1038\&Page=3620\&Index=4. Accessed 3 July 2012).

With such high expectations imposed on them, senior-rank officials are the focus of training and development. Another reason to invest more in Taiwan's top-level personnel training is the aforementioned closed employment system for senior civil servants. Generally speaking, the current civil service recruiting system in Taiwan is flexible enough to encourage outsiders from the private sector to

6 The civil servants listed in Table 10.1 include personnel working in central and local governments. This includes civil servants working in administrative offices, public enterprises, hygiene and medical services, and public schools. Political appointees, elected agency chiefs and public school teachers are excluded. 
enter the public sector at elementary and junior ranks. As indicated previously, depending on the type of civil service examination passed, new public sector entrants typically enter at G1, G3, G6, G7 or G9 grade. Yet as $\mathrm{Su}$ (2010: 614) points out, with a few exceptions, seniorrank positions (G10-G14) are not open to individuals outside the civil service. ${ }^{7}$ Instead, positions categorised G10 or higher can be reached only through regular promotion processes inside the bureaucracy for existing civil servants. Consequently, almost all senior civil servants must serve in the bureaucracy for years before reaching executive level. Though this lengthy process may result in the senior civil service being an experienced team, many lose their ambition and innovation after years of immersion in rigid and tedious red tape (Shih 2006). Therefore, compared with their more diversified junior colleagues in the public sector, the homogeneous senior-rank officials are in greater need of training and development.

\section{Dual-track training system}

Taiwan's unique dual-track training system for senior civil service members has much to do with its complex constitutional and political arrangements. In the spirit of the five-power constitution, which was created by founding father, Dr Sun Yat-sen, the five Central Government branches - the Executive Yuan, Legislative Yuan, Judicial Yuan, Examination Yuan and Control Yuan-are independent and form a system of checks and balances. Among them, the Examination Yuan and Executive Yuan share power and responsibility for the establishment and maintenance of a competent civil service system. Specifically, the two major institutions in charge of senior civil service training are: 1) the NACS of the CSPTC under the Examination Yuan; and 2) the Civil Service Development Institute (CSDI) of DGPA under the Executive Yuan. The bilateral relationship between the two training institutions is shown in Figure 10.1.

7 Before 1994, college professors and citizens holding overseas graduate degrees were eligible to compete in the Senior Special Civil Service Examination, which was held infrequently. After passing the exam, the individual would be assigned to a G10 posting and would become a senior-ranked civil servant. The qualification rate for this Senior Special Examination between 1968 and 1988 was approximately 25 per cent, with 1,946 people competing and 503 passing the examination. The examination - criticised as unfair and often tailor-made for the privilegedwas abolished in 1994. For a detailed discussion, see Shiau (2006). 


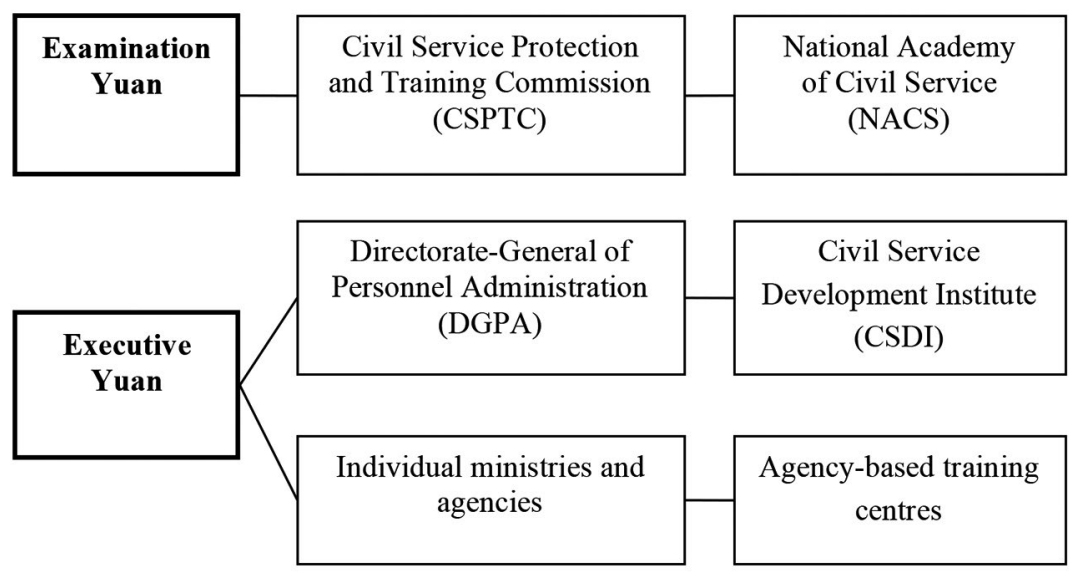

Figure 10.1: Senior-rank civil service training institutions

Source: Created by the author.

According to the 1946 Constitution, the Examination Yuan is the independent authority in charge of making and implementing public personnel policies, including civil service training. However, aiming to strengthen the dominance and influence of executive power, the then ruling party established the Central Personnel Administration(renamed the DGPA in 2012 as part of a larger governmental reorganisation) under the Executive Yuan in 1967. Later, after constitutional amendments and rounds of negotiations between the Executive and Examination yuans, a line was drawn to divide jurisdiction for personnel training between the two branches. The agreement at that time was that the Examination Yuan would focus on training new recruits, rank promotion and political neutrality, while the training of senior servants would be the responsibility of the Executive Yuan, except for those who served in non-executive branches (CSPTC 2000). Specifically, in the jurisdiction of high-ranking personnel training, the Executive Yuan assumed responsibility for public employees affiliated with the Executive Yuan, whereas the Examination Yuan was in charge of training for top officials employed by the other four branches, including the Examination Yuan, Legislative Yuan, Control Yuan and Judicial Yuan. The Executive Yuan is the largest of the five branches in terms of employee size: more than 90 per cent of civil servants work in the Executive Yuan, meaning the Examination Yuan would be implementing top-level civil service training for only 
10 per cent of employees. Therefore, it is clear that, at least before the establishment of NACS of the Examination Yuan, the Executive Yuan played a much more important role in training senior civil servants.

To carry out the training assignments agreed on through negotiations and constitutional amendments, the DGPA of the Executive Yuan set up the CSDI in 1996 and the CSPTC of the Examination Yuan founded the National Civil Service Training Institute in 1999, which was restructured and upgraded to the NACS in 2010. Before 2000, each training institution had its own jurisdiction with regards to training senior civil servants. The division between the Executive and Examination yuans with regards to senior civil service training was clear and unambiguous and there was little duplication or overlap.

In late 2008, however, the new members of the Examination Yuan and its new president, John Kuan, began to change the operation of this dual yet parallel training system. ${ }^{8}$ At that time, the Global Financial Crisis and the resulting economic recession hit the nation hard, and concerns about an incompetent civil service were widespread in society. Hence, with the support of President Ma and the Legislative Yuan, the Examination Yuan successfully modified the CSPTC Organisation Law in 2009, adding medium- and long-term development training for high-level civil servants to the list of its organisational responsibilities. Although the definition and essence of 'medium- and long-term development training' are somewhat ambiguous, the new clause in the CSPTC Organisation Law clearly expands the training jurisdiction for the CSPTC of the Examination Yuan. Previously, the Examination Yuan trained only senior-rank personnel serving in non-executive branches - representing less than 10 per cent of total senior personnel. Now, it has an enlarged jurisdiction reaching all five branches, so long as the program is considered mid- or long-term development training. Essentially, the old parallel dual-track training system - in which two training authorities had different jurisdictions for training and little duplication - has been changed to an overlapping dual-track system. The two training authorities may now target the same group of senior civil servants as potential trainees.

8 The Examination Yuan has a president, vice-president and 19 members, all of whom are special appointees nominated by the nation's President. These individuals are appointed to sixyear terms on confirmation by the Legislative Yuan. All policies and major issues are deliberated and decided on jointly by members at Examination Yuan Council meetings. 
In anticipation of the expanded jurisdiction and a higher training demand, in 2010 the Examination Yuan quickly incorporated the existing NCSI into the NACS. To upgrade the status and influence of the NACS, the chief commissioner of the CSPTC was appointed president of the NACS. This restructuring and empowerment of the NACS is expected to shrink the wide disparity in training capacity between top officials in the Executive and Examination yuans.

Not all civil servants are trained by the NACS or DGPA. As shown in Figure 10.1, in addition to the centralised training provided to senior civil servants by the NACS and DGPA, many ministries and agencies have their own training institutions that cater to their specific portfolio needs and design training curricula that are closely aligned with the ministries' or agencies' goals and responsibilities. For example, judges and prosecutors, police investigators, tax officers, foreign service personnel, auditing officers and others have their own designated training centres that offer agency-based courses. Nevertheless, these agency-based training centres offer numerous and varied training courses, making it difficult to make meaningful comparisons across agencies. Moreover, they usually focus more on elementary- and junior-rank training and give less attention to the training of highlevel civil servants. In consideration of these factors, agency-based training will be excluded from discussion in this chapter.

\section{Training by the DGPA of the Executive Yuan}

Before the Examination Yuan established the NACS, most training for senior civil servants in Taiwan was conducted by the DGPA under the Executive Yuan. This section summarises the training programs provided to senior civil servants by the DGPA in recent years. These programs can be grouped into three categories:

- domestic training

- overseas training

- policy workshops. 


\section{DGPA domestic training programs}

Table 10.2 lists the major domestic training programs organised regularly by the DGPA, including the National Affairs Workshop, Visionary Workshop, Senior Leadership Workshop and Management Excellence Workshop. Each workshop accepts up to 40 trainees - a slightly larger number of participants than the workshops offered by the NACS, where class sizes average 20-30 trainees.

While the NACS of the Examination Yuan restricts its senior service training programs to public officials ranked G10 or higher, the DGPA targets a wider trainee group for the development of executive leadership. The DGPA allows mid-level civil servants about to enter the senior ranks to sit in the same workshop as senior-ranked personnel. As shown in Table 10.2, the Management Excellence Workshop provided by the DGPA accepts trainees ranked G9 or higher. The Management Excellence Workshop is a large training program, with 3,400 mid- to high-level civil servants completing the program in 2009 alone. Civil servants ranked G9 have to pass a rank-promotion civil service exam before reaching G10 grade and being officially counted as senior-ranked civil servants. Allowing G9 personnel likely to enter the senior rank to exchange ideas with their senior colleagues is supposed to benefit both groups. Civil servants ranked G9 are also allowed to participate in overseas training programs offered by the DGPA; this will be discussed later in this chapter. By including G9 personnel in the target group of senior civil service training, the DGPA substantially increases its scope of potential trainees.

Table 10.2: Training programs provided by the DGPA

\begin{tabular}{|l|l|l|l|}
\hline Trainee's rank & Training programs & Number of trainees & Training duration \\
\hline G12 or above & $\begin{array}{l}\text { National Affairs } \\
\text { Workshop }\end{array}$ & $\begin{array}{l}\text { Two workshops per } \\
\text { year and 40 trainees } \\
\text { per workshop }\end{array}$ & $\begin{array}{l}\text { Every Thursday } \\
\text { to Saturday for } \\
\text { six weeks }\end{array}$ \\
\hline G12 or above & $\begin{array}{l}\text { Visionary Leadership } \\
\text { Workshop }\end{array}$ & $\begin{array}{l}\text { One workshop every } \\
\text { two years }\end{array}$ & Two days \\
\hline G11 or above & $\begin{array}{l}\text { Senior Leadership } \\
\text { Workshop }\end{array}$ & $\begin{array}{l}\text { One workshop each } \\
\text { year; } 40 \text { trainees each } \\
\text { workshop, with a minimum } \\
\text { of } 10 \text { female trainees }\end{array}$ & $\begin{array}{l}\text { Every Thursday } \\
\text { to Saturday for } \\
\text { five weeks }\end{array}$ \\
\hline G9 or above & $\begin{array}{l}\text { Management } \\
\text { Excellence Workshop }\end{array}$ & $\begin{array}{l}\text { One workshop every } \\
\text { two years }\end{array}$ & Two days \\
\hline
\end{tabular}

Source: Fang (2009). 


\section{DGPA overseas training programs}

Overseas training for high-level officials has existed for a long time, but it was not until 2008 that the budget allocated for it was substantially increased. In an effort to better connect the knowledge and capacity of high-level civil servants to those on the international scene, the DGPA decided to invest more financial resources in overseas training. A total of 15 groups with more than 500 participants ranked G9 or higher were sent abroad between 2008 and 2010 (Fang 2010: 61-2). Target institutions for overseas cooperation include the John F. Kennedy School of Government at Harvard University, George Washington University, University of Cambridge, London School of Economics and Political Science, Royal Institute of Public Administration in the United Kingdom, Waseda University and the Lee Kuan Yew School of Public Policy at the National University of Singapore. Since 2011, the overseas training program has expanded to accommodate more G9-G14 civil servants for short-term studies. Not only have more foreign institutions been selected as training partners (for instance, the College of Europe in Bruges), but also the DGPA has relaunched a program to send mid- to high-level civil servants to study masters or doctoral degrees abroad (the original program was abolished 18 years ago before being restarted in 2011).

\section{DGPA policy workshops}

In addition to regular domestic programs and various overseas training programs, the DGPA occasionally arranges policy workshops to build necessary competencies for senior civil servants to increase their effectiveness in implementing important policy initiatives. For example, in 2010, 759 trainees ranked G12 and serving as department heads or in higher positions attended the Workshop of Contemporary National Policies (Examination Yuan 2012: 38).

In its early years, the DGPA's training for senior civil servants was not organised in a systematic way; instead most programs were arranged freely or even randomly in accordance with the political and economic needs of the moment. They were mostly conducted under the direction of the Executive Yuan or through proactive planning by the DGPA. The number of workshops for each year was neither fixed nor preplanned, and some often faced the possibility of discontinuation after a few years of operation. However, the types and number of 
training programs designed for senior officials have been increasingly streamlined in recent years, revealing the DGPA's intention to continue its lead and influence in training senior civil service members under the current dual-track training system.

\section{Training by the CSPTC of the Examination Yuan}

In addition to the DGPA of the Executive Yuan, the CSPTC of the Examination Yuan is another important authority in charge of civil service training. The senior civil service training provided by the CSPTC can be divided into two stages. The first stage started in 1996 when the CSPTC was established. During that period the CSPTC was responsible for training senior civil servants affiliated with nonexecutive branches only-namely, the Examination Yuan, Legislative Yuan, Judicial Yuan and Control Yuan. It administered a Senior Executive Training Program designed for G12 and G13 civil servants between 1999 and 2004. In total, 131 trainees attended this program, which required weekly attendance of three days for five weeks.

The CSPTC also carried out six Core Competency Seminars each year for G1 1-G13 bureaucrats from 2005 to 2008. A total of 376 bureaucrats were trained in this program. The six seminars focused on six different core management competencies: innovative vision, strategic analysis, administrative reform, crisis management, interagency coordination and performance management. Each seminar focused on one core competency and took two days to complete. Trainees had to complete all six seminars to receive a certificate. While both programs were well received by high-ranking trainees, a survey indicated that trainees preferred Core Competency Seminars to the Senior Executive Training Program due to the former's shorter training period (Yao 2009: 28). This corroborates the results of other studies that have found that there is little incentive for senior officials to attend training sessions due to their heavy workload (Lai 2011: 44).

The second training stage began in 2010 when the CSPTC assumed responsibility for senior civil servants' medium- and long-term development training and set up the NACS in accordance with the revised Organisational Law. The CSPTC first conducted a survey of 
the core abilities of senior civil servants, the results of which provided a clearer picture of the core competencies that senior civil servants with different grades needed to function properly. Then the CSPTC invited scholars and experts to develop course modules and came up with its major training program, the Take-Off Program for Senior Civil Service 100 (or 'TOP 100'). ${ }^{9}$ The TOP 100 program is arranged into three classes (see Table 10.3). The Management Development Training class is offered to civil servants ranked G10 or G11, and emphasises the enrichment of management capabilities. The course designed for officials ranked G12 to G13 is the Leadership Development Training class, which mainly reinforces leadership capabilities. Civil servants ranked G13 to G14 join the Strategy Development Training class, which focuses on cultivating strategic planning capabilities. The TOP 100 was piloted in 2010 and officially established in 2011. Table 10.3 provides the numbers of program trainees for 2010 and 2011. Acknowledging a low representation of female participants in the first year, efforts were made to increase female participation. Table 10.3 indicates that the percentage of female trainees increased from 19 per cent ( 11 of 58 trainees) in 2010 to 39 per cent ( 22 of 56 trainees) in 2012.

Table 10.3: Number of TOP 100 trainees by sex, 2010-11

\begin{tabular}{|l|c|c|c|c|c|c|c|c|c|}
\hline & \multicolumn{2}{|c|}{$\begin{array}{c}\text { Management } \\
\text { Development Training } \\
(\text { G10-G11) }\end{array}$} & \multicolumn{2}{c|}{$\begin{array}{c}\text { Leadership } \\
\text { Development Training } \\
\text { (G12-G13) }\end{array}$} & \multicolumn{2}{c|}{$\begin{array}{c}\text { Strategy Development } \\
\text { Training (G13-G14) }\end{array}$} \\
\cline { 2 - 11 } & Total & Male & Female & Total & Male & Female & Total & Male & Female \\
\hline 2010 & 25 & 20 & 5 & 24 & 20 & 4 & 9 & 7 & 2 \\
\hline 2011 & 33 & 22 & 11 & 16 & 10 & 6 & 7 & 2 & 5 \\
\hline Total & 58 & 42 & 16 & 40 & 30 & 10 & 16 & 9 & 7 \\
\hline
\end{tabular}

Source: Internal data provided by the NACS.

The TOP 100 training program adopts the approach of assessment centres and provides trainees with comprehensive feedback - the first time such an approach has been systematically adopted in the nation's civil service training. The objective of this time-consuming

9 For more details of the TOP 100 program, see nacs.gov.tw/english/02_projects/02_details. asp?ID=JNOOIRDMONE (accessed 3 July 2012). 
approach is to help trainees understand the gaps in their proficiencies and to recognise the improvements needed through feedback from supervisors, subordinates and peers.

Specifically, the TOP 100 consists of three stages: pre-training, in-training and post-training. During the pre-training period, camp activities are designed to help trainees understand the purpose of training and build the consensus crucial for successful training. In-training - the second stage and the core of the TOP 100 programs - covers 150 hours of courses offered domestically and internationally. ${ }^{10}$ Specifically, it contains 100 hours of core competency courses divided evenly between domestic and foreign study programs, with the remaining 50 hours assigned to general courses. Additionally, depending on need, there may be a customised course of up to 30 hours for individual trainees. In-training in either core competency or general courses relies heavily on case studies, role-play and simulation, field trips and workshops. The last stage of the TOP 100 program is post-training, which is based on recurring training to strengthen the effectiveness of in-training. After completing in-training, trainees are periodically invited to attend keynote speeches and experience-sharing meetings to stay up-to-date on changes in society and international affairs.

\section{Recent developments}

With such a variety of training programs in place, the current quality of senior civil service training in Taiwan is unprecedented in the nation's history. This section summarises the characteristics of the developments observed in Taiwanese senior civil service training in recent years.

First, in designing training curricula for top officials, training authorities, including the Examination and the Executive yuans, have placed a high priority on the acquisition of global vision and knowledge of international affairs. Not only have overseas training

10 The overseas training locations feature notable institutes such as the École Nationale d'Administration (National School of Administration) in France, the National School of Government (NSG) in the United Kingdom, the International Institute for Management Development in Switzerland and the Bundesakademie für öffentliche Verwaltung (BAköV) (Federal Academy of Public Administration) in Germany. 
programs blossomed, but also domestic training courses emphasise brainstorming ideas and cultivating experience under a globalisation framework.

Taiwanese civil servants have encountered difficulties in the global arena in the past few decades due to two significant setbacks in Taiwan's diplomatic history. The first was Taiwan's expulsion from the United Nations, while the second was the end of its formal diplomatic relationship with the United States in 1979, both of which led to diplomatic isolation. In many official meetings and activities with international society and organisations, civil servants from Taiwan are excluded from participation. As a result, Taiwanese civil servants are comparatively lacking in knowledge of and experience in handling international affairs. Although Taiwan's government strives to overcome this limitation through economic and trade relationships, cultural exchanges and other non-official activities, this international reality has negatively influenced the international vision and ability of Taiwanese civil servants. Therefore, investing more resources and manpower is necessary and timely to enhance top officials' connection with the international community through effective training.

Another observation is the active development of diverse training modes and methods. Traditional training courses for senior civil servants are lecture based and do not contain diverse teaching methods. Presently, both the NACS and the DGPA closely follow new trends in training methods. In addition to focused lectures, methods such as group discussions, case analysis, benchmark learning, roleplaying, simulations and digital learning are all actively employed in training. Although trainees perceive greater learning pressures, they generally support the diversification of training methods.

The third recent development in training Taiwan's top-level officials is that there have been more scientific methods used to evaluate and assess training demand and effectiveness. Previously, there was no demand assessment whatsoever to understand the needs of trainees. Although training institutions made efforts to evaluate the effectiveness of their programs, they relied solely on customer satisfaction surveys. Thus, the types and amounts of feedback data that could be gathered were limited. Even though the results of surveys usually showed good levels of satisfaction, concerns regarding ineffective training remained widespread. Additionally, satisfaction 
surveys were generally administered immediately after the training, whereas the effectiveness of training may be perceived or may emerge after some time has passed. For instance, Warr et al. (1970) propose that outcome evaluation of training should focus on the achievements gained from the activity, to be assessed at three levels: a) immediate; b) intermediate; and c) ultimate evaluation. Therefore, post-training tracking assessments are necessary to overcome the limitations of gathering information through satisfaction surveys. In response, the NACS established the Assessment and Development Centre as one of its key internal organisations. The centre attempts to conduct working capability assessments of trainees after training. Analysis reports on their capabilities before and after training are then provided to trainees and a customised individual follow-up program is offered to reinforce the effectiveness of training. ${ }^{11}$

The more active use of the public-private partnership (PPP) model is another notable development of the current training system. From the outset, both the NACS and the DGPA have relied substantially on individuals from universities and the business sector to serve as instructors of training courses. Visits to comparable private enterprise organisations are also frequently arranged for trainees. Nevertheless, exchanges with private enterprises, think tanks and universities have grown even more important in recent years. Both the NACS and the DGPA emphasise making strategic alliances with domestic and foreign training institutes, universities, non-profit organisations and enterprises for greater interchange with and connection to the outside world. In addition to jointly organising or sponsoring a wide range of conferences, seminars and workshops with universities and foundations, training institutions have started several other publicprivate collaborations. For example, the DGPA has outsourced many activities, including contracting the management of its CSDI facilities to a private corporation and outsourcing to universities evening classes for civil servants' advanced studies. Another example is in the TOP 100 program designed by the NACS, which regularly invites university professors and leaders of non-profit organisations or businesses to attend training sessions with civil servants, with the aim of establishing a platform for public-private interchanges.

11 The Assessment and Development Centre is a new organisation. It is too early to conclude whether it is well equipped to successfully design and implement customised individual followup programs. 
Apart from the above-mentioned PPP models employed in the training of high-ranking officials, the government also encourages senior civil servants to study for course credits or academic degrees in universities by offering tuition subsidies and official study leave. As a result, there has been a surge in the number of academic organisations offering masters programs for public employees. For example, more than 80 per cent of the students enrolled in the Executive Master of Public Administration program of the National Taiwan University in the past 12 years have been civil servants; of these, more than one-third have been senior-ranked civil servants. It is expected that the wide adoption of PPP models by centralised training authorities will not only save money and manpower for the government, but also, more importantly, result in more flexibility and greater effectiveness in civil service training.

The fifth characteristic of recent developments in senior civil service training is an increase in female trainees. Though the increase is not significant, it is nonetheless encouraging. Studies show that it takes much more effort for female civil servants to be promoted in the public sector due to the well-known 'glass ceiling' that subtly blocks their advancement (Naff 1994). Official civil service statistics from 2011 revealed that although female civil servants outnumbered male civil servants in administrative agencies, with females comprising 50.4 per cent and males 49.6 per cent, the ratio of females who reached senior rank was only 26.9 per cent to the 73.1 per cent of male senior civil servants (MOCS 2012). Nevertheless, as the gender gap in educational achievements continues to shrink and awareness of women's rights increases in Taiwan, we are optimistic that the current gender inequality in the civil service will gradually improve (Su 2010: 612). In fact, this change is already reflected in the training of senior civil servants. In the past few years, the government has intensified efforts to train and develop high-ranking female officials. For instance, the Executive Yuan offered a leadership development workshop exclusively for female senior civil servants. The TOP 100 program is also attentive to the ratio of female to male trainees during its selection process.

The final development worth mentioning is the repeated emphasis on enhancing top officials' communication skills with the mass media through government training. For decades before the end of martial law, Taiwan's authoritarian government controlled the media. 
However, since the 1990s, aggressive growth in the media industry, along with the dynamic development of political and societal forces, has resulted in rapid changes in Taiwan's media environment (Hong 1999; Rawnsley 2007; Kao 2010). The rapid expansion of the media has led to oversupply, excessive competition and aggressiveness in industry practices. It seems that a lack of journalistic ethics and standards sometimes triggers unnecessary tensions between the bureaucracy, the media and the public. There have been many instances in which, due to poor or improper communication with the media, crucial public policy initiatives have failed to win public support and public officials have been forced to step down from their positions. Hence, training institutions have begun to invite experts who specialise in dealing with the media to offer tips and share experiences with senior civil servants. Thus, communicating with the media has become a new type of core competency for senior civil servants, a skill that was not previously considered important in the old insulated bureaucratic environment.

\section{Future challenges and prospects}

Although favourable improvements have been made to training senior civil servants in Taiwan under the active efforts of the NACS and DGPA, three important challenges remain. The first results from the competition and cooperation of the unique dual-track training system. Before the CSPTC of the Examination Yuan amended its Organisation Act in 2009, the jurisdiction of senior civil servants who could be trained by the CSPTC did not include subordinate organisations under the Executive Yuan. Instead, its training jurisdiction was restricted to personnel employed by the Examination, Legislative, Judicial and Control yuans. Therefore, its supply of potential trainees was rather limited, creating an obstacle in the establishment of a systematic training mechanism for senior civil servants. After the Act was amended, the CSPTC acquired a legal basis for taking charge of the medium- to long-term development training of senior civil servants, which caused an overlap in training targets with the Executive Yuan. Since the cohort of senior civil servants in Taiwan is small, the overlap in training targets has generated some subtle competition between the two training authorities. 
Therefore, the imminent challenge is how to effectively coordinate training activities offered by the two institutions. Presently, senior civil servants are trained separately by the Executive and Examination yuans, which by constitutional authority are independent of each other and have fixed boundaries. Thus, an effective mechanism of coordination and communication between the two training institutions - whether formal or informal - is not easily established. The goal of reducing the costs of negotiation and coordination to ensure that the training programs provided by both institutions are mutually complementary and effective is sometimes difficult to achieve. In fact, the mechanism in place is currently claimed to be ineffective (Examination Yuan 2012: 24).

There is no denying that the dual-track system in Taiwan has created a number of benefits due to healthy competition, and institutions being more active and engaged in training endeavours. Nevertheless, in the future, because of the intrinsic departmental rivalry and possibly poor coordination, the dual-track system may lead to resource wastage in the form of duplicated courses or repetitive personnel training. In particular, the budgetary resources allocated to training are unlikely to increase significantly due to the huge fiscal pressures the government faces. When the dual-track system divides these limited resources between the two institutions, it may hinder the utilisation of the advantages of the economies of scale. As such, it will be an important, though challenging, task for the Examination and Executive yuans to break through each other's boundaries and reduce coordination costs to better integrate training resources and maximise the effectiveness of senior civil servant training.

The second challenge faced by the Taiwanese Government is strengthening the connection between training performance and career advancement. Studies indicate that, if successful completion of a training program has minimal correlation with work incentives such as recognition, pay scale and job promotion, civil servants' motivation to participate in training decreases (Noe 1986; Clark et al. 1993; Huque and Vyas 2008). In Taiwan, promotion-related training for elementary to junior ranks and junior to senior ranks offers a strong incentive for bureaucrats in the elementary and junior ranks to participate in training. By law, they cannot advance further in the bureaucratic system without completing promotion-related training programs. However, for senior civil servants, training is almost entirely unrelated 
to future job assignment or promotion. Apart from applying newly acquired skills in the work setting, their good performance in training programs leads to little desirable reward. Therefore, the likelihood that senior civil servants will be willing to squeeze time out of their busy work schedules to voluntarily attend training programs is low.

In response to top officials' unwillingness to participate in training, the Examination Yuan has formulated a plan to integrate the TOP 100 program into future job assignments. According to the plan, top officials ranked G10 and Gll can be recommended to participate in Management Development Training. On successful completion of training, participants will be included in the talent pool for future G12-rank promotions. Similarly, civil servants ranked G12 and G13 who have completed Leadership Development Training and civil servants ranked G13 and G14 who have completed Strategy Development Training will qualify for the Senior Civil Service Special Management System (SCSSMS), giving them priority for promotion into top positions in ministries or agencies.

However, the SCSSMS planned by the Examination Yuan involves the right of appointment by the leaders of the ministry or agency. Presently, more than 98 per cent of senior civil servants serve in the Executive Yuan and its constituent organisations, which are outside the scope of authority of the Examination Yuan. To put the idea of the SCSSMS into practice requires the consent and cooperation of the Executive Yuan. It may take some time before a consensus is reached and the plan implemented. This once again illustrates the unavoidable coordination costs involved in the current dual-track system of civil servant training.

The final challenge is the question of how to ensure value for money in the training system. This is undoubtedly an issue facing training institutions all over the world. As indicated earlier, increasingly more scientific methods have attempted to evaluate the effectiveness of training for senior civil servants in Taiwan. However, these attempts are still in their early stages. Since civil servants are trained to answer to the public and be accountable for their behaviour and decisions, training institutions must also have the responsibility to demonstrate that their services offer value for money. For instance, the overseas learning emphasised by both the NACS and the DGPA is costly. Is there a systematic tracking system in place to objectively compare the costs 
and benefits of domestic and overseas programs? It is clear that only when value for money is proved can concerns about the legitimacy of the current dual-track training system be put to rest.

\section{Conclusion}

The democratisation and globalisation experienced in Taiwan in past years have produced bureaucratic passivity and a decline in executive leadership. As a result, better and more effective training for senior public servants has become essential for improving national competitiveness. Through competition between two training authorities - the NACS of the Examination Yuan and the DGPA of the Executive Yuan - the scale of top civil service training in Taiwan has risen to unprecedented levels in recent years. A variety of training programs, both domestic and overseas, is offered. While global perspective, strategic management and policy innovation are the most essential themes for training courses, communicating effectively with a media industry that is particularly hard to deal with is considered a new core competency for top-ranking officials in this newly democratised society.

In addition to two common challenges often encountered by other countries - creating a stronger link between training and job assignment and demonstrating value for money for training programs - Taiwan has faced a unique challenge in the form of its dual-track training system, coordination of which must be improved. As argued by Landau (1991), a two-organisation arrangement does not necessarily produce waste or duplication. Instead, it may bring more reliability into a system. So far, we have witnessed healthy competition between the NACS and the DGPA, resulting in:

1. the provision of more systemised training programs

2. an emphasis on global vision and international connection

3. the adoption of diverse training modes and methods

4. the use of scientific methods in the assessment of demand and training effectiveness

5. the inclusion of different resources in broader Taiwanese society to form public-private partnerships in training

6. the participation of more female trainees. 
Nevertheless, as an exploratory study, this chapter does not conclude that the current dual-track training system is the best institutional choice for training Taiwanese senior civil servants. How significant are the communication and coordination costs incurred under this dual-track system? Will it save more money if the training authority has the power to combine all budgetary resources so as to fully utilise the benefits of an economy of scale? These types of questions await further study. In the meantime, given the reality that the five-power constitution will continue for years to come in Taiwan and that its accompanying dual-track civil service training system is also unlikely to change in the foreseeable future, it is essential to build an effective mechanism for responsibility sharing and better coordination between the two training authorities.

\section{References}

Berman, E. M., Chen, D.-Y. and Huang, T.-Y. 2012. Public agency leadership: The impact of informal understandings with political appointees on perceived agency innovation in Taiwan. Journal of Public Administration: 1-22.

Cheung, A. B. 2005. The politics of administrative reforms in Asia: Paradigms and legacies, paths and diversities. Governance 18(2): 257-82.

Civil Service Protection and Training Commission (CSPTC) 2000. Special Report on the Establishment of CSPTC. [In Chinese]. Taipei: Civil Service Protection and Training Commission.

Clark, C. 2000. Democracy, bureaucracy, and state capacity in Taiwan. International Journal of Public Administration 23(10): 1833-53.

Clark, C. S., Dobbins, G. H. and Ladd, R. T. 1993. Exploratory field study of training motivation: Influence of involvement, credibility, and transfer climate. Group \& Organisation Management 18: 292-307.

Examination Yuan 2012. The Examination Yuan's Plan for the Improvement of Civil Service Training. [In Chinese]. Taipei: The Examination Yuan. 
Fang, S.-W. 2009. The training of mid to high level civil servants in the Executive Yuan: Current status and future prospects. [In Chinese]. Personnel Monthly 49(4): 15-22.

Fang, S.-W. 2010. The Executive Yuan's plan of civil service training. [In Chinese]. Personnel Monthly 51(3): 58-64.

Felsenthal, D. S. 1980. Applying the redundancy concept to administrative organisations. Public Administration Review 40: $247-52$.

Hong, J. 1999. Globalization and change in Taiwan's media: The Interplay of political and economic forces. Asian Journal of Communication 9(2): 39-59.

Huque, A. and Vyas, L. 2008. Expectations and performance: Assessment of public service training in Hong Kong. International Journal of Human Resource Management 19(1): 188-204.

Kao, S.-C. 2010. Media culture in Taiwan: The case of Taiwanese nationalism. Paper presented at the 18th Biennial Conference of the Asian Studies Association of Australia, Adelaide, 5-8 July.

Knott, J. H. and Miller, G. J. 1987. Reforming Bureaucracy: The politics of institutional choice. Englewood Cliffs, NJ: Prentice-Hall.

Lai, F.-Y. 2011. The transformation of senior civil service training in a globalized world. [In Chinese]. Forum on Training and Development 130: $40-58$.

Landau, M. 1969. Redundancy, rationality and the problem of duplication and overlap. Public Administration Review 29(4): 346-58.

Landau, M. 1991. On multi-organisational systems in public administration. Journal of Public Administration 1(January): 5-18.

Lerner, A. W. 1987. There is more than one way to be redundant. Administration and Society 18(3): 334-59. 
Ministry of Civil Service of the Republic of China (Taiwan)(MOCS) 2012. Table 19: Number of civil servants of administration agency (end of 2011). All Civil Services Database. Taipei: MOCS. Available from: mocs.gov.tw/pages $/$ detail.asp ? Node $=1038 \&$ Page $=3620 \& I n d e x=4$ (accessed 3 July 2012) (site discontinued).

Naff, K. C. 1994. Through the glass ceiling: Prospects for the advancement of women in the federal civil service. Public Administration Review 54(6): 507-14.

Noe, R. A. 1986. Trainees' attributes and attitudes: Neglected influences on training effectiveness. Academy of Management Review 11(4): 736-49.

Painter, M. 2004. The politics of administrative reform in East and Southeast Asia: From gridlock to continuous self-improvement? Governance 17(3): 361-86.

Rawnsley, G. D. 2007. The media and democracy in China and Taiwan. Taiwan Journal of Democracy 3(1): 63-78.

Shiau, J.-Y. 2006. A comparative study of civil service recruitment systems in Taiwan and China. Masters thesis [In Chinese]. National Chengchi University, Taipei.

Shih, J. N. 2006. Capacity of civil service system and government competitiveness: Strategic human resource management perspective. [In Chinese]. Soochow Journal of Political Science 22: $1-46$.

Su, T.-T. 2010. Civil service reforms in Taiwan. In E. Berman, M. J. Moon and H. Choi (eds), Public Administration in East Asia: Mainland China, Japan, South Korea and Taiwan, 609-26. New York: CRC Press.

Tan, Q. 2000. Democratization and bureaucratic restructuring in Taiwan. Studies in Comparative International Development 35(2): $48-64$.

Tang, C.-P. 2004. When new public management runs into democratization: Taiwan's public administration in transition. Issues \& Studies 40(3-4): 59-100. 
Wade, R. 1990. Governing the Market: Economic theory and the role of government in East Asian industrialization. Princeton, NJ: Princeton University Press.

Warr, P. B., Bird, M. and Rackham, N. 1970. The Evaluation of Management Training. London: Gower Press.

Yao, S.-Q. 2009. The impact of senior civil service training in Taiwan: A case study of CSPTC's training programs. [In Chinese]. T\&D Fashion 83: 1-29. 
This text is taken from Sharpening the Sword of State: Building executive capacities in the public services of the Asia-Pacific, edited by Andrew Podger and John Wanna, published 2016 by ANU Press, The Australian National University, Canberra, Australia. 